\title{
Da atividade à invalidez permanente: um estudo utilizando dados do Regime Geral de Previdência Social (RGPS) do Brasil no período 1999-2002
}

\author{
Marília Miranda Forte Gomes* \\ Moema Gonçalves Bueno Fígoli** \\ Aloísio Joaquim Freitas Ribeiro***
}

\begin{abstract}
Este trabalho tem como objetivo estimar as probabilidades de transição de um indivíduo entre os estados de atividade e invalidez permanente, segundo sexo e idade, para os segurados do Regime Geral de Previdência Social - RGPS no período 1999-2002. Os resultados mostram que o risco de se aposentar por invalidez, para os homens, é crescente até os 65 anos de idade e depois diminui. Para as mulheres, as probabilidades de entrada em aposentadoria por invalidez são crescentes até a última idade considerada. O padrão observado pode ser explicado, entre outros motivos, pela competitividade do risco de se aposentar por invalidez com os outros benefícios cobertos pelo sistema previdenciário, caso o segurado tenha adiado ou não tenha cumprido a carência mínima exigida para requerer a concessão de tais benefícios. Por ser uma tábua adequada para a massa de participantes de um regime previdenciário, este trabalho contribui para um maior conhecimento sobre a invalidez, principalmente nas áreas de seguro e previdência.
\end{abstract}

Palavras-chave: Tábuas de vida. Previdência. Invalidez permanente.

\section{Introdução}

Conforme consagrada na Constituição Federal, a seguridade social no Brasil é constituída por três elementos: seguro social, assistência social e saúde. Particularmente, o seguro social, também conhecido como previdência social, constitui um programa de pagamentos em dinheiro e/ou serviços prestados ao indivíduo e/ou seus dependentes, geralmente condicionado à preexistência de um vínculo contributivo ao sistema como compensação parcial ou total da perda de capacidade laborativa, que pode ser efetiva ou presumida (OLIVEIRA et al., 2004). Nesse universo, a Previdência Social brasileira define invalidez como a incapacidade do segurado para o trabalho, insuscetível de reabilitação para o exercício de atividade que lhe garanta a subsistência (BRASIL, 1999).

No Brasil, todos os trabalhadores segurados da Previdência Social estão cobertos contra a perda de renda devido à invalidez

\footnotetext{
* Estatística, Mestre em Demografia e Doutoranda do programa de Pós-graduação em Demografia do Centro de Desenvolvimento e Planejamento Regional - Cedeplar, da Universidade Federal de Minas Gerais - UFMG. Bolsista Fapemig.

** Doutora em Demografia pela Universidade Federal de Minas Gerais - UFMG, pesquisadora e professora associada do Departamento de Demografia do Centro de Desenvolvimento e Planejamento Regional - Cedeplar, da Universidade Federal de Minas Gerais - UFMG.

*** Doutor em Demografia pelo Centro de Desenvolvimento e Planejamento Regional - Cedeplar, da Universidade Federal de Minas Gerais - UFMG, professor adjunto do Departamento de Estatística, da Universidade Federal de Minas Gerais - UFMG.
} 
permanente resultante de doença ou lesão, por meio do benefício de aposentadoria por invalidez, que será concedido ao segurado, estando ele ou não em gozo de auxíliodoença. ${ }^{1}$

Destaca-se que o número concedido de benefícios de aposentadoria por invalidez pela Previdência Social brasileira tem crescido significativamente nos últimos 20 anos. Segundo dados históricos do Anuário Estatístico da Previdência Social (2007), do total de aposentadorias concedidas pelo RGPS, em 2000, 22\% foram por invalidez, proporção que aumentou para 30\%, em 2005. Entre 1990 e 1995, observou-se um acréscimo de $0,7 \%$ nas entradas em invalidez permanente. No período seguinte (1995-2000), esse incremento foi de 5,6\% e, entre 2000-2005, correspondeu a 11,6\%. Esses aumentos se refletem também nas despesas do sistema previdenciário com o referido benefício. De 2000 a 2005, por exemplo, a despesa média do RGPS com aposentadorias por invalidez quase triplicou quando comparada à do período anterior (1995-2000).

Para que o sistema possa estabelecer uma fonte de custeio para esses benefícios de aposentadoria por invalidez, é necessário que o mesmo conheça o fluxo desses benefícios. Para o cálculo desses fluxos, são utilizadas probabilidades de transição de um segurado entre os estados de atividade e invalidez permanente, geralmente apresentadas na forma de uma das funções das tábuas de vida. A tábua que descreve como ocorre a transição da atividade para a invalidez permanente é conhecida como Tábua de Entrada em Aposentadoria por Invalidez.

As probabilidades de entrada em invalidez permanente, implícitas na Tábua de Entrada em Aposentadoria por Invalidez, têm impacto sobre o custo estimado dos benefícios de aposentadoria por invalidez. Quanto maiores as probabilidades de transição de um segurado entre os estados de atividade e invalidez permanente, maiores serão os fluxos esperados e, consequente- mente, os aumentos no estoque trarão gastos mais elevados com aposentadorias por invalidez. Caso essas probabilidades sejam mal estimadas, o sistema poderá enfrentar sérios problemas de gestão, principalmente no campo econômico-atuarial. Assim, é importante que as probabilidades de entrada em invalidez sejam constantemente revistas, para manter a proximidade com a realidade que o sistema previdenciário está vivenciando naquele momento.

O Brasil ainda é deficitário com relação a tábuas de vida para grupos populacionais específicos, levando o regime previdenciário brasileiro a utilizar tábuas que refletem experiências demográficas antigas ou de outras populações. Evidências dessa situação são as tábuas definidas pela legislação sobre planos de previdência privada aberta - Resolução do Conselho Nacional de Seguros Privados $n^{\circ}$ 092, de 2002 (CNSP, 2002) - e pela legislação referente aos regimes próprios de governos dos servidores públicos - da Portaria do Ministério da Previdência e Assistência Social, n 4.992, de 1999 (MPAS, 1999; RIBEIRO, 2006). Essas legislações estabelecem a Tábua de Entrada em Invalidez Álvaro Vindas como limite mínimo para as probabilidades de entrada em aposentadoria por invalidez. Essa tábua foi elaborada em 1957, pelo estatístico Álvaro Vindas, para o Departamento Atuarial e Estatístico da Caja Costarricense de Seguro Social - CCSS (MAGALHÃES; BUGARIN, 2004; PINHEIRO, 2005). ${ }^{2}$

Tendo em vista a relevância que os estudos sobre invalidez têm para o sistema previdenciário, o objetivo deste trabalho é estimar as probabilidades de entrada em invalidez permanente, implícitas em uma Tábua de Entrada em Aposentadoria por Invalidez, segundo sexo e idade, para os segurados do Regime Geral de Previdência Social - RGPS, com base nos dados obtidos entre 01/01/1999 e 31/12/2002, considerando-se exclusivamente as aposentadorias por invalidez previdenciárias. Não foram consi-

\footnotetext{
1 O auxílio-doença é o benefício devido ao segurado nos casos de incapacidade temporária para o trabalho, decorrente de doença ou lesão cuja duração seja superior a 15 dias (BRASIL, 1999).

2 Outras tábuas de entrada em invalidez também utilizadas pelo mercado previdenciário brasileiro são: Light (1973) e IAPB (1957), ambas construídas com base em experiências brasileiras, além das tábuas que traduzem a experiência de empresas de consultorias americanas, tais como Mercer MW Disability e Towers.
} 
deradas as aposentadorias por invalidez acidentárias porque possuem características e regras diferenciadas de concessão quando comparadas às previdenciárias. Além disso, elas representam apenas $4,9 \%$ das aposentadorias por invalidez concedidas pelo RGPS no período em estudo.

$\mathrm{Na}$ construção da Tábua de Entrada em Aposentadoria por Invalidez, segundo sexo e idade, para os segurados do RGPS no período 1999-2002, foram utilizados os registros administrativos da Empresa de Tecnologia e Informações da Previdência Social - Dataprev, informações sobre contribuintes da Previdência Social do Cadastro Nacional de Informações Sociais - CNIS e tábuas de mortalidade, por sexo e idade, estimadas para o Brasil e disponíveis no sítio do Instituto Brasileiro de Geografia e Estatística - IBGE.

Os segurados especiais não foram incluídos na estimativa das taxas de entrada em aposentadoria por invalidez, que considerou apenas os indivíduos que realizaram pelo menos uma contribuição no ano. Como a contribuição dos segurados especiais é sobre a receita bruta da comercialização da produção rural e muitos deles produzem apenas para o próprio consumo e não para a comercialização, os mesmos se encontram subenumerados nas informações sobre o número de contribuintes. Vale comentar que a maioria desses segurados, por lei, comprova carência mínima necessária à concessão do benefício requerido com base no tempo de efetivo exercício de atividade rural e a atual legislação garante a eles benefício de auxílio-doença ou de aposentadoria por idade ou invalidez no valor de um salário mínimo (BRASIL, 1999; MPS/ INSS/DATAPREV, 2007). Ao considerá-los no cálculo das taxas de entrada em invalidez, estas poderiam ser superestimadas, pois os segurados especiais não estariam devidamente contabilizados no denominador, já que só são verdadeiramente conhecidos na concessão dos benefícios. ${ }^{3}$ Assim, a população de estudo deste trabalho foi composta por todos os segurados urbanos e rurais, excluindo-se os segurados especiais.

Ressalta-se que o padrão e o nível implícito na tábua que será apresentada neste trabalho representam a experiência de entrada em aposentadoria por invalideze não a entrada em invalidez no seu conceito mais amplo, incluindo todos os indivíduos inválidos. Para a construção dessa tábua, a informação disponível é o número de pessoas que entraram em aposentadoria por invalidez pela previdência social e não o número de segurados que se invalidaram. Assim, nela não estão incluídas as pessoas que, em gozo de outros benefícios de prestação continuada, ${ }^{4}$ se invalidaram, já que não existe no INSS a opção de transformação desses benefícios em aposentadoria por invalidez, e nem aquelas que, mesmo inválidas, optaram por outro tipo de aposentadoria, por ser mais vantajosa economicamente. Além disso, o simples fato de a previdência oferecer vários tipos de benefícios ao mesmo tempo torna-os competitivos entre eles, afetando os valores das taxas. Isso dito, a Tábua de Entrada em Aposentadoria por Invalidez, segundo sexo e idade, é adequada para a massa de participantes pertencentes a um regime previdenciário.

\section{Aposentadoria por invalidez: o benefício de invalidez permanente}

A aposentadoria por invalidez será devida ao segurado que, estando ou não em gozo de auxílio doença, for considerado incapaz para o trabalho e insuscetível de reabilitação para o exercício de atividade que Ihe garanta a subsistência enquanto permanecer nessa condição. Trata-se, portanto, de um benefício garantido aos segurados permanentemente inválidos para a realização de qualquer trabalho. A verificação da condição de incapacidade permanente é

\footnotetext{
3 Por exemplo, segundo dados do MPS/Dataprev para o período 1999-2002, enquanto os segurados especiais representavam aproximadamente $0,06 \%$ do total de contribuintes, um pouco mais de $10 \%$ dos beneficiários de aposentadoria por invalidez eram segurados especiais.

4 Benefícios de prestação continuada são caracterizados por pagamentos mensais contínuos, até que alguma causa (a morte, por exemplo) provoque a sua cessação. Enquadram-se nesta categoria as aposentadorias, pensões por morte, rendas mensais vitalícias, abonos de permanência em serviço, os salários-família e maternidade, etc. (MPS/INSS/DATAPREV, , 2007).
} 
realizada mediante exame médico-pericial, a cargo da previdência social, podendo o segurado, às suas expensas, estar acompanhado de um médico de sua confiança. A doença ou lesão existente na data de filiação ao RGPS não habilita o segurado ao direito à aposentadoria por invalidez, exceto quando a incapacidade sobrevier por motivo de progressão ou agravamento dessa doença ou lesão (BRASIL, 1999).

Segundo o Regulamento da Previdência Social (1999), a concessão do benefício de aposentadoria por invalidez está condicionada ao cumprimento de um período de carência de doze contribuições mensais. Caso o trabalhador, após a perda da qualidade de segurado, tenha se filiado novamente ao RGPS, a aposentadoria por invalidez dependerá do cumprimento de quatro contribuições mensais. Contudo, a concessão de aposentadorias por invalidez independe de carência tanto nos casos resultantes de acidente de qualquer natureza ou causa, ${ }^{5}$ como em situações em que, após filiar-se ao RGPS, o segurado for acometido de alguma das doenças ou afecções especificadas em uma lista elaborada e atualizada a cada três anos pelos Ministérios da Saúde e da Previdência Social. A última lista foi publicada mediante a Portaria Interministerial $n^{\circ} 2.998$, de 23 de agosto de 2001, e inclui as seguintes doenças: tuberculose ativa, hanseníase, alienação mental, neoplasia maligna, cegueira, paralisia irreversível e incapacitante, cardiopatia grave, estado avançado da doença de Paget - osteíte deformante, Síndrome da Imunodeficiência Adquirida Aids, contaminação por radiação com base em conclusão da medicina especializada e hepatopatia grave (BRASIL, 1999). Desde 1991, não houve mudança das doenças apresentadas nessa lista.

A concessão de aposentadoria por invalidez, inclusive mediante transformação de auxílio-doença, está condicionada também ao afastamento de todas as atividades. Quando o segurado exerce mais de uma atividade e fica incapacitado definitivamente para uma delas, o auxíliodoença será mantido indefinidamente, não ocorrendo sua transformação em aposentadoria por invalidez, enquanto essa incapacidade não se estender às demais atividades (BRASIL, 1999).

Diferentemente das aposentadorias por idade e tempo de contribuição, que são vitalícias, a aposentadoria por invalidez cessa quando a perícia médica do INSS conclui pela recuperação da capacidade laborativa do segurado ou quando esse retorna voluntariamente ao trabalho. $\mathrm{O}$ aposentado por invalidez que não se submeter aos exames médico-periciais bienalmente também terá o seu benefício cancelado. Outros motivos para a cessação desse benefício são: morte do aposentado; transformação em outro benefício - observado o cumprimento das exigências mínimas necessárias na data de início do benefício a ser transformado; e constatação de fraude ou erro administrativo.

De acordo com os Anuários Estatísticos da Previdência Social - AEPS, a aposentadoria por invalidez pode ser classificada em acidentária ou previdenciária. A principal diferença entre as duas é que esta última resulta de um acidente de trabalho ocorrido durante o exercício do trabalho a serviço da empresa, ou no percurso entre a residência e o local de trabalho. Além disso, o direito à aposentadoria por invalidez acidentária independe do número de contribuições realizadas junto ao RGPS pelo segurado acidentado. Por sua vez, o benefício de aposentadoria por invalidez previdenciária só será concedido ao segurado inválido para o trabalho que cumpriu o período de carência mínimo estabelecido em lei. Neste estudo, foram consideradas apenas as aposentadorias por invalidez previdenciárias, que representaram $95,1 \%$ das aposentadorias por invalidez concedidas pelo RGPS, no período 1999-2002.

\footnotetext{
5 Os acidentes de qualquer natureza ou causa são definidos como aqueles de origem traumática e por exposição a agentes exógenos (físicos, químicos e biológicos), que acarretem lesão corporal ou perturbação funcional, resultando na morte, na perda ou na redução permanente ou temporária da capacidade laborativa (BRASIL, 1999; RIBEIRO, 2006).
} 


\section{Alguns estudos relacionados à invalidez na previdência no Brasil}

O Brasil é um país carente de estudos sobre invalidez, principalmente nas áreas de seguro e previdência. Poucos são os trabalhos que procuraram retratar as entradas e saídas dos segurados do RGPS, seja na condição de beneficiários de aposentadorias por invalidez, seja na qualidade de outros benefícios (RIBEIRO, 2006). Situação semelhante também é observada para os segurados dos regimes próprios de previdência social dos servidores públicos e militares, assim como para os segurados da previdência complementar.

Segundo Castro (1997), o número reduzido de estudos sobre as entradas e saídas dos segurados do RGPS devia-se, principalmente, à precariedade e às limitações das informações. Contudo, a autora ressalta que, desde a década de 1990, o MPS tem se esforçado para melhorar a abrangência e a qualidade dos dados, de tal forma que se possa conhecer melhor quem são os seus segurados, viabilizando assim um número maior de trabalhos nessa área.

Entre os estudos relacionados à invalidez no Brasil, destaca-se primeiramente aquele realizado por Oliveira (1985), que, apesar das limitações dos dados disponíveis, elaboraram um modelo para simular o número de contribuintes e beneficiários da previdência social, considerando, para tanto, um modelo markoviano de primeira ordem. As tendências futuras da população em estudo foram estimadas com base nas probabilidades de transição - entradas e saídas - entre os diversos estados do sistema, como, por exemplo, de contribuintes para aposentados por invalidez ou para aposentados por idade. Embora pioneiro, o trabalho não apresenta os resultados numéricos dessas taxas, impossibilitando a comparação com outros estudos da mesma área.

Buscando suprir parte da carência de informações sobre as probabilidades de entrada e saída do sistema previdenciário, Castro (1997) analisou as entradas nos benefícios de auxílio-doença, aposentadorias por idade, invalidez e tempo de serviço e as saídas, por morte, dos benefícios de renda mensal vitalícia e das aposentadorias por idade, invalidez e tempo de serviço dos segurados do RGPS. No cálculo dessas probabilidades de transição, para a estimativa das entradas, foram utilizadas tábuas de múltiplos-decrementos e, para as saídas, tábuas de mortalidade simples.

Para estimar as taxas de entrada em qualquer um dos benefícios estudados, Castro (1997) utilizou dados dos registros administrativos da Empresa de Tecnologia e Informações da Previdência Social Dataprev e das Pesquisas Nacionais por Amostra de Domicílios - PNADs de 1990 e 1995. O número de entradas para cada um dos benefícios foi obtido com base nos dados da Dataprev. Diante da ausência de informações sobre os segurados ativos do RGPS, este número foi extraído da PNAD, considerando-se as pessoas economicamente ativas, acrescidas dos estudantes e das pessoas que cuidavam dos afazeres domésticos, excluindo-se, portanto, os pensionistas e os aposentados. Sabendo-se ainda que a população exposta ao risco de receber um benefício está sujeita à morte, a autora estimou os óbitos dos segurados a cada idade, aplicando-se taxas específicas de mortalidade disponibilizadas em tábuas de mortalidade fornecidas pelo IBGE.

Outro estudo sobre invalidez utilizando dados do RGPS foi realizado recentemente por Ribeiro (2006), que descreve o padrão de mortalidade dos aposentados por invalidez de clientela urbana, a partir da construção de tábuas seletas e últimas de mortalidade para homens e mulheres do RGPS, entre 01/01/1999 e 31/12/2002. Nessas tábuas, as probabilidades de morte dependem da idade de entrada em aposentadoria por invalidez e da duração deste benefício. Entre as conclusões do estudo, Ribeiro (2006) destaca que o efeito da duração da invalidez sobre as taxas de mortalidade foi maior nos primeiros anos de aposentadoria, diminuindo com o aumento da idade alcançada pelo beneficiário. $\mathrm{O}$ autor destaca ainda que, quanto mais cedo ocorrer a entrada em invalidez e quanto maior for a sua duração, maiores serão os custos para o sistema previdenciário. Por isso, para a realização de projeções atua- 
riais de beneficiários, é necessário que se conheçam também as probabilidades de entrada em invalidez.

Por sua vez, Pinheiro (2005), utilizando dados administrativos relativos a segurados de planos de previdência complementar, ressalta a importância da escolha de uma tábua adequada para cálculos de seguros. Em seu trabalho, o autor avalia as principais tábuas utilizadas pelo mercado previdenciário brasileiro, aplicando testes de aderência para as premissas demográficas, tais como mortalidade, morbidade (entrada em invalidez), rotatividade e geração futura de novos entrados, nos planos de benefício definido e de contribuição definida, administrados por um fundo de pensão. Os resultados mostraram que $75 \%$ das probabilidades implícitas nas tábuas analisadas e utilizadas pelo mercado previdenciário modificam o impacto sobre as reservas matemáticas dos benefícios programados de aposentadorias por invalidez, principalmente para os empregados no início de carreira profissional. Isso significa que, se as probabilidades de entrada para a invalidez forem mal estimadas, os fundos de pensão poderão enfrentar sérios problemas de gestão, seja no campo econômico-atuarial, seja no jurídico.

\section{Aspectos metodológicos}

\section{Bases de dados}

\section{Registros administrativos da Dataprev}

Os registros administrativos da Dataprev na forma de microdados referem-se aos benefícios segundo a espécie, ativos em algum momento entre 01/01/1998 e $31 / 12 / 2003$. Cada linha do banco de dados corresponde a um benefício e não a um beneficiário. No caso das aposentadorias, cada benefício corresponde a um beneficiário, pois não é permitida a acumulação de aposentadorias (RIBEIRO, 2006).

A seguir, são descritas as variáveis desse banco de dados utilizadas para descrever como ocorre a transição da atividade para a invalidez, dos segurados do RGPS.

- Grupo de espécie de benefício: identifica o tipo de benefício que o indivíduo recebe. Esta variável está subdividida em aposentadoria por idade, invalidez ou tempo de serviço, auxílio-doença, auxílio-doença acidentário e aposentadoria acidentária.

- Clientela: classificação do benefício em urbano ou rural. Esta classificação não segue as mesmas regras do conceito de situação do domicílio adotado pelo IBGE. Para a Previdência Social, um benefício é considerado urbano ou rural segundo o ramo de atividade ao qual pertence o segurado.

- Sexo: classificado como ignorado, masculino ou feminino.

- Data de nascimento: ano de nascimento do beneficiário.

- Data de início do benefício - DIB: mês e ano do início de recebimento do benefício, ou seja, é a data de entrada no sistema previdenciário. Essa informação, quando comparada com o ano de nascimento do beneficiário, permite calcular a idade do segurado no momento em que passou a receber algum benefício.

- Idade: em anos completos, em relação à DIB.

- Forma de filiação do beneficiário no RGPS: refere-se à condição de filiação do segurado no momento em que este passa a ter direito ao recebimento de algum benefício. A filiação à previdência social decorre automaticamente do exercício de atividade remunerada, para os segurados obrigatórios, e da inscrição formalizada com o pagamento da primeira contribuição, para o segurado facultativo. Possui as seguintes categorias: empregado, empregado doméstico, contribuinte individual, trabalhador avulso ou facultativo, desempregado, empresário, optante pela Lei 6.184/74 e segurado especial.

- Situação do benefício no RGPS na data de extração dos dados: se ativo, suspenso, excluído ou cessado.

- Faixa de duração para ativos: permite obter a distribuição da duração dos benefícios ativos em 31 de dezembro de 1998, 1999, 2000, 2001 e 2002. 
- Causa de invalidez que originou a concessão do benefício: classificada segundo os códigos da Classificação Internacional de Doença-CID. Foram disponibilizadas as informações registradas na primeira e na última perícia realizada pelo segurado com ano da DIB maior ou igual a 1980. Para 1998 e 1999 , foram utilizadas a 9a e a $10^{a}$ revisões da Classificação Internacional de Doenças - CID. As aposentadorias por invalidez concedidas após 1999 têm as suas causas classificadas segundo a CID 10.

Contribuintes da Previdência Social do Cadastro Nacional de Informações Sociais - CNIS

As informações sobre os contribuintes da Previdência Social são provenientes do CNIS, que constitui uma base de dados nacional com informações sobre trabalhadores (empregados, trabalhadores avulsos, contribuintes individuais e facultativos, empregados domésticos e segurados especiais) e empregadores. Seus dados são provenientes de diversos instrumentos, tais como: Programa de Integração Social - PIS; Programa de Formação do Patrimônio do Servidor Público - Pasep; Relação Anual de Informações Sociais - Rais; Cadastro Geral de Empregados e Desempregados - Caged; Guia de Recolhimento do Contribuinte Individual - GRCl; Guia da Previdência Social - GPS e Guia de Recolhimento do Fundo de Garantia do Tempo de Serviço e Informações à Previdência Social - GFIP, sendo este último o mais relevante para a base de dados do CNIS (MPS/INSS/DATAPREV, 2007).

As informações disponibilizadas sobre os contribuintes do RGPS contemplam a quantidade de trabalhadores que efetuaram pelo menos uma contribuição mensal durante o ano-calendário, para cada ano do período 1998-2002, segundo sexo, idade simples e tipo de contribuinte (empregados, trabalhadores avulsos, contribuintes individuais, facultativos, domésticos, segurado especial e indeterminado). Nessas infor- mações, o trabalhador que possuía mais de um emprego foi contado apenas uma vez, ou seja, a unidade de referência para a mensuração foi o contribuinte.

Tábuas de mortalidade fornecidas pelo IBGE

Para estimar o número de óbitos ocorridos entre a população exposta ao risco de se aposentar por invalidez no período 1999-2002, foram utilizadas tábuas de mortalidade anuais estimadas para o Brasil, no período em estudo, pelo Departamento de População e Indicadores Sociais - Depis, do IBGE, segundo sexo e grupos de idade quinquenal (www.ibge.gov.br). Para se obterem as tábuas de mortalidade por idade simples, as funções de sobrevivência Ix das tábuas disponibilizadas pelo Depis/IBGE, segundo sexo e grupos de idade quinquenal, foram desagregadas utilizando-se os multiplicadores baseados na fórmula de Karup-King, ${ }^{6}$ sendo que as respectivas probabilidades de morte foram obtidas segundo sexo e idade simples.

\section{Definição formal das medidas de entrada em invalidez}

A medida básica para a construção de uma Tábua de Entrada em Aposentadoria por Invalidez é a probabilidade de entrada em invalidez $-{ }_{n} \mathrm{r}_{x}$, que representa o risco que um segurado sobrevivente à idade $x$ tem de se aposentar por invalidez entre as idades $x$ e $x+n$, no intervalo de tempo $t$, dado que ele não se encontra inválido permanentemente para o trabalho. Segundo Jordan (1967), essas probabilidades podem ser calculadas pela expressão: ${ }_{n} \mathrm{r}_{x}=\frac{{ }_{n} \mathrm{i}_{x}}{1_{x}^{\text {aa }}}(1)$, onde:

${ }_{n} i_{x}$ corresponde ao número de entradas em invalidez, entre as idades $x$ e $x+n$ anos, no período de observação; e $1_{x}^{\text {aa }}$ refere-se ao número de sobreviventes segurados expostos ao risco de se aposentar por invalidez que atinge a idade exata $x$, no período de observação.

\footnotetext{
6 Mais informações sobre essa técnica podem ser obtidas em Shryock e Siegel (1980) e Siegel e Swanson (2004).
} 
$\mathrm{Na}$ prática, as probabilidades de entrada em aposentadoria por invalidez são obtidas aproximadamente em função das taxas de entrada em aposentadoria por invalidez $-{ }_{n} \mathrm{r}_{x}^{\prime}$, pressupondo-se que a população exposta ao risco sobrevivente à idade exata $x$ varia linearmente com a idade. Assim, as probabilidades de entrada em invalidez podem ser representadas por:

${ }_{n} \mathrm{r}_{x}=\frac{2 \mathrm{x}_{n} \mathrm{r}_{x}^{\prime}}{2+{ }_{n} \mathrm{r}_{x}^{\prime}}$

Onde: ${ }_{n} \mathrm{r}_{x}^{\prime}=\frac{{ }_{n} \mathrm{i}_{x}}{{ }_{n} \mathrm{~L}_{x}^{\mathrm{aa}}}$ (3), considerando que:

${ }_{n} \mathrm{r}_{x}$ ' corresponde à taxa de entrada em invalidez, entre as idades $x$ e $x+n$ anos, no período de observação; ${ }_{n} i_{x}$ é o número de entradas em invalidez, entre as idades $x$ e $x+n$ anos, no período de observação; e ${ }_{n} \mathrm{~L}_{x}^{\text {aa }}$ refere-se ao número de pessoas-ano expostas ao risco de se aposentar por invalidez entre as idades $x$ e $x+n$, no período de observação.

Vale lembrar que as medidas apresentadas nas fórmulas 1, 2 e 3 correspondem à invalidez permanente ou total para o trabalho - definida como aquela que impossibilita o segurado de exercer atividade que Ihe garanta a subsistência - e, portanto, a recuperação da capacidade laborativa caracterizada pela volta ao trabalho não é considerada nos seus cálculos (JORDAN, 1967).

\section{Os riscos competitivos}

Para o cálculo das medidas de transição do estado de atividade para invalidez permanente, é necessário levar em conta os riscos competitivos, tendo em vista que o sistema previdenciário oferece outros benefícios. Enquanto ativos, os segurados do regime previdenciário em estudo estão expostos ao risco de morte e invalidez, ou ainda podem se aposentar por tempo de contribuição ou idade e também perder a qualidade de segurado.

No entanto, essas transições diferenciam-se quanto às condições de concessão dos benefícios, em que se destacam os limites de idade e o período de carência. A aposentadoria por tempo de contribuição, por exemplo, uma vez cumprida a carência exigida, é devida ao segurado que completa, no mínimo, 35 anos de contribuição, se do sexo masculino, e 30 anos, se do sexo feminino. Normalmente, as entradas nesse benefício concentram-se entre os 45 e 55 anos de idade. Por sua vez, a aposentadoria por idade, quando cumprida a carência de 180 contribuições mensais, será concedida ao segurado que completar 65 anos de idade, se homem, ou 60 anos, se mulher, reduzidos esses limites para 60 e 55 anos para os trabalhadores rurais, respectivamente homens e mulheres. ${ }^{7}$ Nos intervalos etários em que estão inseridas essas idades mínimas para concessão de benefício de aposentadoria por idade, é observado o maior número de entradas nesse benefício. Ao considerar que essas possibilidades atuam sobre a população exposta ao risco de se aposentar por invalidez e são os únicos decrementos possíveis, incluindo a morte e a perda da qualidade de segurado, é possível calcular a probabilidade de entrada para invalidez permanente, considerando-se que todos os outros decrementos estão atuando. Dessa maneira, a estimativa das probabilidades propostas neste trabalho será mais fidedigna, uma vez que, ao levar em conta que a população em estudo está exposta apenas ao risco de se aposentar por invalidez em uma situação de riscos competitivos, as respectivas probabilidades seriam sobre-estimadas (SEAL, 1977; WINKLEVOSS, 1993).

Sabendo-se disso, as hipóteses e o método para calcular as probabilidades

\footnotetext{
7 A carência mínima exigida para que um segurado do RGPS faça jus ao recebimento de aposentadorias por idade, tempo de contribuição e especial é de 180 contribuições mensais. Até 1992, eram exigidos apenas 60 meses. A partir de 1992, a carência para os segurados que já estavam inscritos no RGPS até meados de 1991 passou a ser acrescida de seis meses cada, de tal forma que, em 2012, todos os segurados se enquadrem em 180 meses de carência. Além disso, os trabalhadores rurais foram equiparados aos urbanos, devendo passar a efetuar contribuições para o RGPS. Para aqueles trabalhadores rurais já enquadrados no sistema previdenciário antes da Lei 8.213/91, é permitida a concessão de aposentadoria por idade, sem comprovação de contribuição, no valor de um salário mínimo, até julho de 2006 (CASTRO, 1997). Mais informações sobre as regras associadas à concessão, manutenção e cessação dos benefícios de aposentadoria por idade e tempo de contribuição ou outros benefícios cobertos pelo RGPS podem ser consultadas em Brasil (1991 e 1999).
} 
de entrada em invalidez permanente para os segurados do RGPS, segundo sexo e idade, são apresentados na seção seguinte. Para o cálculo das taxas de entrada em aposentadoria por invalidez, ajustaram-se seus denominadores, levando-se em conta a competitividade da concessão da aposentadoria por invalidez com os outros benefícios concedidos pelo RGPS e com a morte, de tal forma que esses denominadores representassem, o mais próximo possível, o tempo total de exposição somente ao evento em estudo.

\section{Cálculo das taxas de entrada em} aposentadoria por invalidez e os dados disponíveis: limitações e pressupostos adotados

O número de entradas em invalidez permanente, segundo sexo e idade, foi obtido como o número de benefícios de aposentadoria por invalidez iniciados entre 01/01/1999 e 31/12/2002. Para a estimativa do denominador das taxas de entrada em aposentadorias por invalidez, seriam necessários dados que representassem a história de vida no RGPS de cada um dos segurados, contendo informações como tempo de contribuição, datas de entrada e saída no sistema previdenciário, benefícios recebidos e cessados por cada um dos segurados, entre outros, o que possibilitaria calcular o tempo total de exposição ao risco em invalidez. No entanto, as informações disponíveis referem-se ao número de contribuintes empregados, trabalhadores avulsos, empregados domésticos, trabalhadores individuais e segurados facultativos, que efetuaram pelo menos uma contribuição mensal ao longo de cada ano do período 1999-2002. Ao considerar que o tempo total de exposição ao risco em análise é igual ao número de contribuintes em cada ano do período em estudo, pressupõe-se que cada contribuinte ficou exposto ao risco durante todo o período, o que não é verdade.

Os dados disponibilizados sobre contribuintes no ano incluem aqueles que tiveram algum benefício concedido durante $\mathrm{o}$ ano. Como eles só estiveram expostos ao risco de se invalidar parte do ano, o uso dessa informação, sem correção, poderia supe- restimar o tempo de exposição ao risco em estudo, subestimando as taxas de entrada em aposentadoria por invalidez.

Como uma tentativa para solucionar esse problema, subtraiu-se, do número de contribuintes que realizaram pelo menos uma contribuição ao longo de cada ano do período 1999-2002, a metade das aposentadorias por idade, invalidez e tempo de contribuição observada em cada ano do mesmo período, supondo-se que esses indivíduos estiveram, em média, expostos ao risco de se aposentar por invalidez metade do intervalo de tempo considerado, ou seja, as entradas nesses benefícios ocorreram uniformemente durante os anos do período considerado. As entradas em auxílio-doença não foram descontadas do denominador, porque esses beneficiários, mesmo deixando de ser contribuintes ao longo do ano, continuavam expostos ao risco de se aposentar por invalidez e, assim, devem ser contabilizados como contribuintes durante $o$ ano inteiro.

Os dados disponíveis contemplam também os contribuintes que morreram em algum momento de cada ano do período em estudo e foram computados como se estivessem expostos o ano inteiro ao risco de se aposentar por invalidez. Para reduzir essa possível superestimação do denominador, pressupôs-se que os contribuintes estimados conforme indicado no parágrafo anterior, por sexo e idade simples, experimentaram as mesmas probabilidades de morte estimadas em tábuas de mortalidade do Depis/IBGE para a população total brasileira, no período 1999-2002. A correção do número de pessoas-ano foi feita subtraindo-se, do número de contribuintes ajustados segundo o procedimento mencionado no parágrafo anterior, a metade dos óbitos estimados para cada ano do período 1999-2002, sob o pressuposto de que esses óbitos se distribuíram uniformemente ao longo de cada ano do período em estudo.

Segundo o Regulamento da Previdência Social (1999), a concessão do benefício de aposentadoria por invalidez está condicionada ao cumprimento de um período de carência de 12 ou 4 contribuições, caso o trabalhador, após a perda da qualidade 
de segurado, tenha se filiado novamente ao RGPS. Infelizmente, não se tem conhecimento da história contributiva dos trabaIhadores segurados do RGPS e a utilização direta das informações disponíveis pode subestimar as taxas de entrada em invalidez por esse motivo, pois não necessariamente todos os contribuintes no ano atendem à carência mínima exigida para a concessão do benefício em estudo. Além disso, as taxas também podem ser subestimadas porque não é possível verificar quais desses contribuintes, durante os anos em estudo, cumpriram a carência mínima exigida para se aposentar por invalidez e, portanto, estiveram expostos ao risco em análise apenas parte do intervalo de tempo. Este caso pode ser exemplificado pelo trabalhador segurado que completou 12 contribuições para o RGPS em 10 de setembro do ano $t$ e ficou exposto ao risco de se aposentar por invalidez quatro meses, e não o ano todo.

Por outro lado, o segurado que deixou de exercer atividade remunerada abrangida pela previdência social ou esteve suspenso ou licenciado sem remuneração, só deixará de fazer parte do grupo de segurados doze meses após a cessação de benefício por incapacidade temporária ou permanente, ou após a cessação das contribuições. Mesmo que esses indivíduos não tenham realizado nenhuma contribuição ao longo do ano, eles permaneceram expostos ao risco de se aposentar por invalidez parte do ano - por exemplo, o indivíduo que teve o seu auxílio-doença cessado em agosto do ano $t$ permanece segurado até agosto do ano $t+1$, ainda que não tenha realizado nenhuma contribuição após a cessação do benefício. A inexistência de informações que representem essas situações subestima o denominador e, consequentemente, superestima as taxas, pois uma parte importante desses indivíduos não é contabilizada nos dados sobre contribuintes do CNIS.
Diante das limitações dos dados disponíveis, as taxas de entrada em aposentadoria por invalidez foram calculadas a partir da hipótese de que os efeitos ocasionados pela inexistência das informações destacadas nos dois parágrafos anteriores se compensam e a estimativa do tempo total de exposição ao risco em estudo não é prejudicada significativamente.

Outra limitação da informação disponível que foi considerada para a estimativa da população coberta contra a perda de renda devido à invalidez permanente refere-se ao incremento no denominador dos beneficiários ativos que estiveram em auxílio-doença durante todo o ano. Segundo o Regulamento da Previdência Social (1999), a aposentadoria por invalidez será devida ao segurado estando ele ou não em gozo de auxílio-doença. Isto indica que aqueles indivíduos em auxílio-doença continuam ativos para exercer atividade que lhe garanta a subsistência, ou seja, estão expostos ao risco de se aposentar por invalidez, mas, como não realizaram nenhuma contribuição no ano, não foram computados na base de dados sobre contribuintes do CNIS. Nesse caso, a utilização da informação disponível, sem considerar esses segurados, poderia superestimar as taxas. Vale ressaltar que as pessoas que estavam em auxílio-doença e retornaram ao trabalho durante o ano, ou que tiveram esse benefício concedido ao longo do ano estão computadas nas informações do CNIS, uma vez que realizaram pelo menos uma contribuição no ano.

A análise das limitações dos dados disponíveis e a busca de soluções para os problemas destacados permitiram estimar 0 tempo de exposição ao risco de se aposentar por invalidez mais próximo da realidade. Em linhas gerais, as taxas de entrada em invalidez permanente para os segurados do RGPS, no período 1999-2002, segundo sexo e idade, foram obtidas pela seguinte expressão:

$$
\begin{aligned}
{ }_{n} \mathrm{r}_{x}^{1999-2002}= & \left\{\left[{ }_{n} C_{x}^{1999}-\frac{{ }_{n} E_{x}^{1999}}{2}\right]-\frac{{ }_{n} D_{x}^{1999}}{2}+{ }_{n} A_{x}^{1999}\right\}+\left\{\left[{ }_{n} C_{x}^{2000}-\frac{{ }_{n}^{1999-2002} E_{x}^{2000}}{2}\right]-\frac{{ }_{n} D_{x}^{2000}}{2}+{ }_{n} A_{x}^{2000}\right\}+ \\
& +\left\{\left[{ }_{n} C_{x}^{2001}-\frac{{ }_{n} E_{x}^{2001}}{2}\right]-\frac{{ }_{n} D_{x}^{2001}}{2}+{ }_{n} A_{x}^{2001}\right\}+\left\{\left[{ }_{n} C_{x}^{2002}-\frac{{ }_{n} E_{x}^{2002}}{2}\right]-\frac{{ }_{n} D_{x}^{2002}}{2}+{ }_{n} A_{x}^{2002}\right\}
\end{aligned}
$$


Onde:

${ }_{n} i_{x}^{1999-2002}$ : número de entradas em aposentadorias por invalidez, entre as idades $x$ e $x+n$ anos, no período 1999-2002;

${ }_{n} C_{x}^{y}$ : número de contribuintes no ano $y$, entre as idades $x$ e $x+n$ anos, onde $\mathrm{y}=1999,2000$, 2001 e 2002;

${ }_{n} E_{x}^{y}$ : aposentadorias por idade, por tempo de contribuição e por invalidez concedidas no ano $y$, entre as idades $x$ e $x+n$ anos, onde $\mathrm{y}=1999,2000,2001$ e 2002;

${ }_{n} D_{x}^{y}=\left({ }_{n} C_{x}^{y}-{ }_{n} E_{x}^{y}\right) \times{ }_{n} q_{x}^{y}$ : número de contribuintes que morreram no ano $y$, entre as idades $x$ e $x+n$ anos, onde ${ }_{n} q_{x}^{y}$ é a probabilidade de morte que uma pessoa, tendo alcançado a idade exata $x$, tem de morrer entre as idades $x$ e $x+n$ anos, onde $\mathrm{y}=1999,2000$, 2001 e 2002;

${ }_{n} A_{x}^{y}$ : número de beneficiários ativos que estiveram em auxílio-doença durante todo $\mathrm{o}$ ano $y$, entre as idades $x$ e $x+n$ anos, onde $\mathrm{y}=1999,2000,2001$ e 2002.

Ressalta-se que, embora os segurados do RGPS estejam expostos ao risco de se aposentar por invalidez desde a sua filiação, o que pode acontecer a partir dos 15 anos - caso o segurado seja um menor aprendiz - ou a partir dos 17 anos - para os demais segurados, neste trabalho foram consideradas apenas as informações para as idades de entrada em invalidez permanente entre 20 e 70 anos.

A escolha do limite inferior de 20 anos deveu-se ao pequeno número de casos de aposentados por invalidez antes dessa idade no período 1999-2002. Para o limite superior, a ideia inicial, também proposta por Ribeiro (2006), era considerar as idades mínimas exigidas para concessão de aposentadorias por idade. Como o universo de estudo inclui segurados rurais e urbanos - portanto, com idades mínimas exigidas para concessão de aposentadorias por idade diferenciadas - e o número de aposentadorias por invalidez concedidas no período 1999-2002 após os 60 anos foi significativo, estabeleceu-se a idade máxima de entrada em aposentadoria por invalidez aos 70 anos. Após esta idade, observaramse também no período em estudo poucos casos de entrada em aposentadorias por invalidez - aproximadamente $1,4 \%$ do total dos benefícios concedidos.

Definidas as taxas de entrada em invalidez para os segurados do RGPS no período 1999-2002, segundo sexo e idade simples, as mesmas foram suavizadas utilizando-se os multiplicadores baseados na fórmula de Karup-King. ${ }^{8}$ Com base nessas taxas suavizadas - nrn" -, as probabilidades de entrada em aposentadoria por invalidez - nrn - foram calculadas, segundo sexo e idade, utilizandose a fórmula (2) apresentada anteriormente.

Estabelecidas as probabilidades de entrada em invalidez, a Tábua de Entrada em Aposentadoria por Invalidez foi então construída para os segurados do RGPS, no período 1999-2002, segundo sexo e idade.

\section{Características gerais das entradas em aposentadorias por invalidez e dos contribuintes no período 1999-2002}

Entre 01/01/1999 e 31/12/2002, foram iniciados 547.193 benefícios de aposentadorias por invalidez previdenciárias, ${ }^{9}$ dos quais $524.259(95,8 \%)$ eram de clientela urbana e $330.306(60,3 \%)$ referiam-se ao sexo masculino. A idade mediana desses aposentados na data de início do benefício - DIB, no mesmo período, correspondia a 51 anos, para os homens, e 54 anos, para as mulheres. No geral, a composição etária dos aposentados por invalidez, na DIB em estudo, foi mais envelhecida para as mulheres.

Os benefícios de aposentadoria por invalidez previdenciária iniciados entre 01/01/1999 e 31/12/2002 foram também analisados segundo sexo, idade e condição de filiação do segurado. O Gráfico 1 mostra que os aposentados por invalidez do sexo masculino eram, na sua maioria, empregados e desempregados. No entanto, ao analisar a composição etária dos homens aposentados por invalidez em relação à DIB (Gráfico 2), observam-se declínio da

\footnotetext{
8 Mais informações sobre essa técnica, bem como os multiplicadores utilizados, podem ser obtidas em Shryock e Siegel (1980) e Siegel e Swanson, (2004)

9 Exclusive os segurados especiais.
} 
participação dos segurados empregados e aumento dos individuais e facultativos, principalmente depois dos 65 anos.

Para as mulheres, no total, as entradas em aposentadoria por invalidez foram mais frequentes entre as seguradas individuais
(Gráfico 1). Nas idades mais avançadas, as aposentadorias por invalidez se dão basicamente entre as filiadas seguradas individuais e facultativas, como pode ser observado no Gráfico 2. Provavelmente, essas são também as posições na ocupação em que se encontra

GRÁFICO 1

Distribuição relativa, na DIB, dos beneficiários de aposentadoria por invalidez do RGPS, por sexo, segundo forma de filiação Brasil - 01/01/1999-31/12/2002

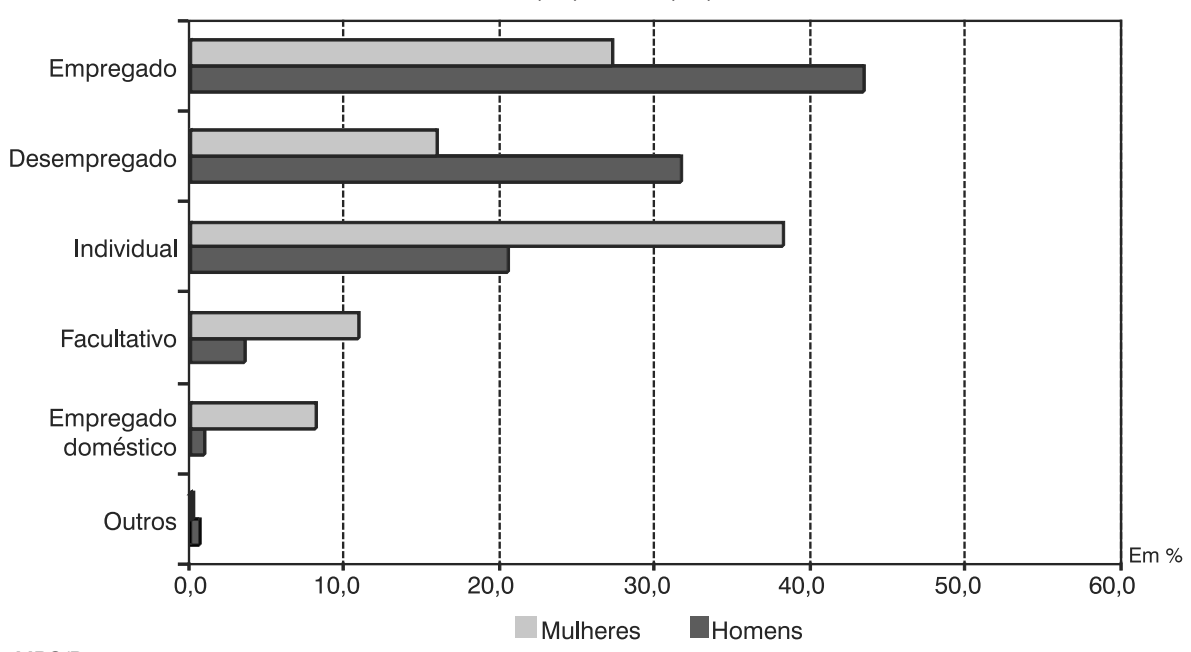

Fonte: MPS/Dataprev

GRÁFICO 2

Distribuição, na DIB, dos beneficiários de aposentaria por invalidez do RGPS, por sexo, segundo grupos de idade e forma de filiação

Brasil - 01/01/1999-31/12/2002
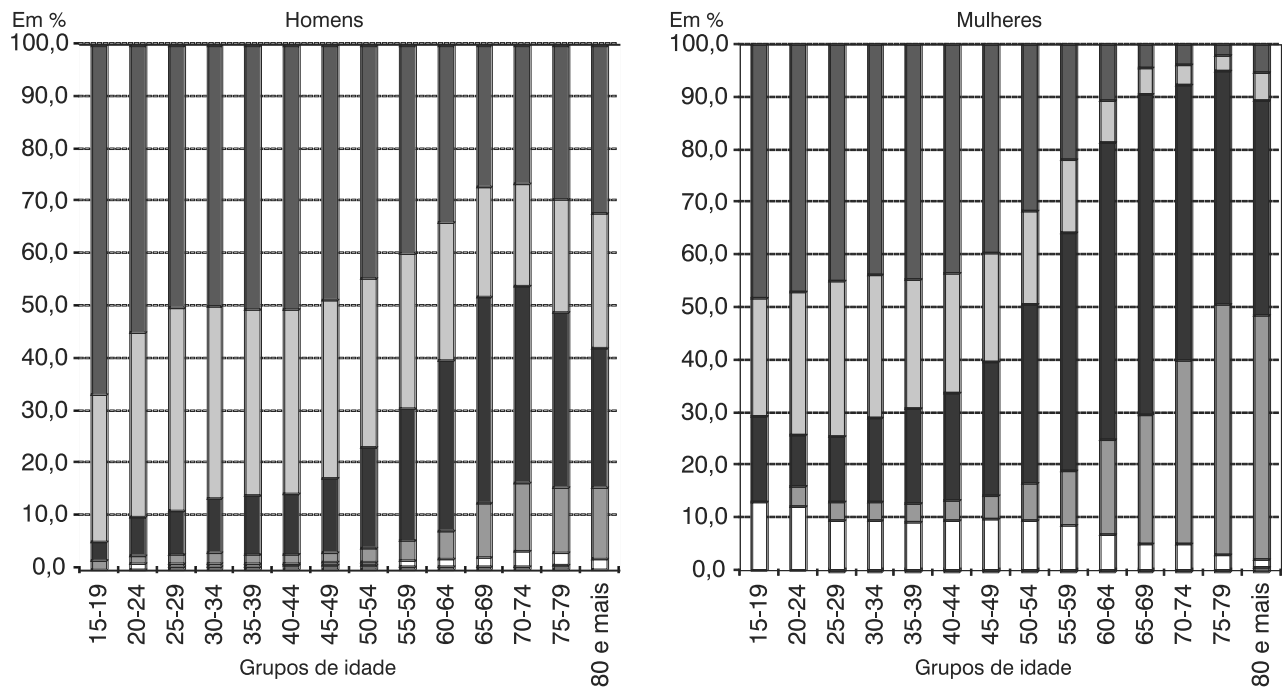

Empregado $\square$ Desempregado $\square$ Individual $\square$ Facultativo $\square$ Doméstico $\square$ Outros 
a maioria das mulheres seguradas com 60 anos ou mais. Nessas categorias ocupacionais, as mulheres, normalmente, ingressam no RGPS tardiamente e possuem trajetórias de contribuição muito irregulares, de tal modo que não satisfazem a carência mínima exigida para concessão do benefício de aposentadoria por tempo de contribuição ou por idade nas idades mínimas previstas. Assim, elas continuam expostas por mais tempo e em maior número ao risco de invalidez.

No período 1999-2002, as doenças do aparelho circulatório foram a principal causa de concessão de aposentadoria por invalidez, sendo responsável por $29,2 \%$ das entradas. Em seguida, vieram as doenças osteomusculares e mentais, representando, respectivamente, $19,5 \%$ e $12,4 \%$ do total. As lesões foram muito mais elevadas entre os homens (Gráfico 3).

No que diz respeito às características dos contribuintes no período 1999-2002, observa-se, na Tabela 1, que a sua maioria era de empregados (82\%) e do sexo masculino (61\%). Destaca-se o número de mulheres na categoria outros contribuintes. No geral,

GRÁFICO 3

Distribuição, na DIB, dos benefícios de aposentadoria por invalidez do RGPS, por sexo, segundo causas de invalidez

Brasil - 01/01/1999-31/12/2002

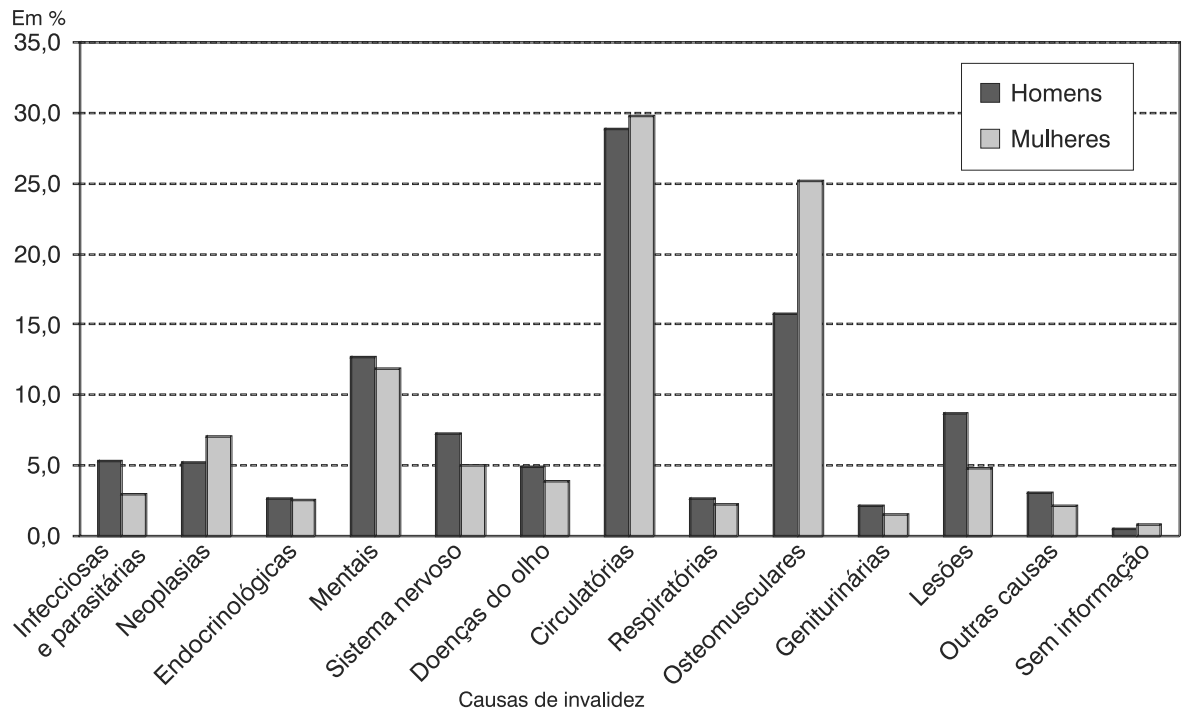

Fonte: MPS/Dataprev.

TABELA 1

Número de contribuintes, por categoria e sexo, segundo grupos de idade Brasil - 1999-2002

\begin{tabular}{|c|c|c|c|c|c|c|c|c|c|}
\hline \multirow{2}{*}{$\begin{array}{l}\text { Grupos de } \\
\text { idade }\end{array}$} & \multicolumn{3}{|c|}{ Empregados } & \multicolumn{3}{|c|}{ Outros contribuintes } & \multicolumn{3}{|c|}{ Total } \\
\hline & Homens & Mulheres & Total & Homens & Mulheres & Total & Homens & Mulheres & Total \\
\hline Até 30 anos & 33.070 .231 & 18.797 .529 & 51.867 .760 & 1.990 .116 & 3.489 .580 & 5.479 .696 & 35.060 .347 & 22.287 .109 & 57.347 .456 \\
\hline $31-40$ anos & 20.619 .843 & 11.055 .060 & 31.674 .903 & 2.742 .596 & 3.684 .394 & 6.426 .990 & 23.362 .439 & 14.739 .454 & 38.101 .893 \\
\hline $41-50$ anos & 12.383 .514 & 6.163 .351 & 18.546 .865 & 2.878 .459 & 3.450 .495 & 6.328 .954 & 15.261 .973 & 9.613 .846 & 24.875 .819 \\
\hline 51-65 anos & 5.568 .839 & 2.093 .695 & 7.662 .534 & 2.333 .588 & 2.960 .325 & 5.293 .913 & 7.902 .427 & 5.054 .020 & 12.956 .447 \\
\hline $\begin{array}{l}66 \text { anos e } \\
\text { mais }\end{array}$ & 466.867 & 103.848 & 570.715 & 242.264 & 178.442 & 420.706 & 709.131 & 282.290 & 991.421 \\
\hline Total & 72.109 .294 & 38.213 .483 & 110.322.777 & 10.187 .023 & 10.100 .200 & 23.950.259 & 82.296 .317 & 51.976 .719 & 134.273.036 \\
\hline
\end{tabular}

Fonte: CNIS/Previdência Social.

Nota: Conforme classificado nas informações disponibilizadas pelo CNIS, a categoria empregados inclui os contribuintes empregados e os trabalhadores avulsos. Por sua vez, a categoria outros contribuintes inclui os contribuintes individuais, facultativos e domésticos. 
aproximadamente $43 \%$ dos contribuintes possuíam até 30 anos de idade.

\section{O padrão implícito na Tábua de Entrada em Aposentadoria por Invalidez construída}

Estabelecidas as probabilidades de entrada em invalidez permanente (Gráfico 4), admitiu-se um grupo inicial hipotético de 100.000 segurados, que estariam expostos anualmente ao risco de se aposentar por invalidez. A Tábua de Entrada em Aposentadoria por Invalidez para os segurados do RGPS, no período 1999-2002, segundo sexo e idade, encontra-se na Tabela 2.

Antes de dar início à análise das probabilidades de entrada em aposentadoria por

GRÁFICO 4

Probabilidades de entrada em invalidez para os segurados do RGPS, por sexo, segundo idade Brasil - 01/01/199931/12/2002

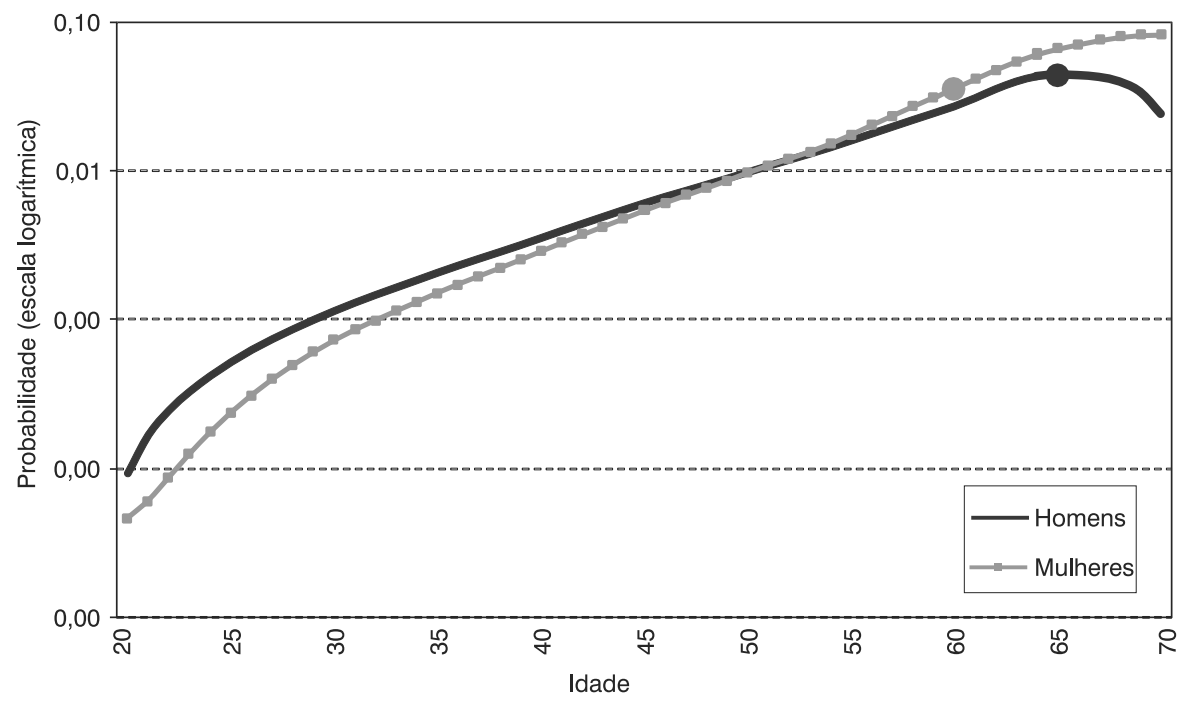

Fonte: MPS/Dataprev.

GRÁFICO 5

Distribuição das entradas em aposentadorias por idade, invalidez e tempo de contribuição entre os segurados do RGPS, por sexo, segundo grupos de idade Brasil - 01/01/1999-31/12/2002

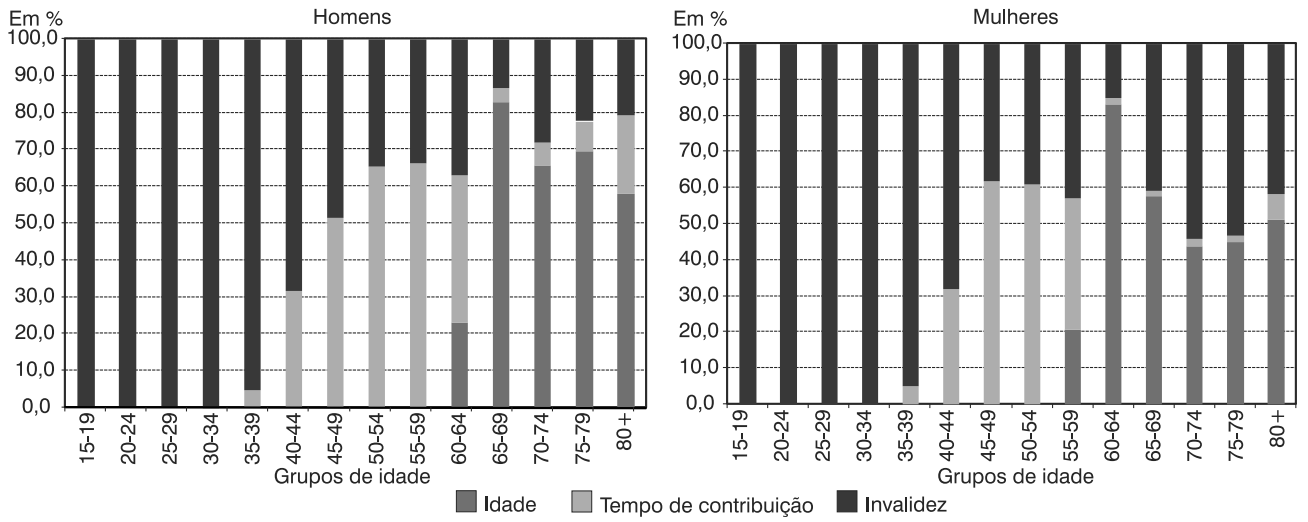

Fonte: MPS/Dataprev. 
TABELA 2

Tábua de Entrada em Aposentadoria por Invalidez para os segurados do RGPS, por sexo, segundo idade Brasil - 01/01/1999-31/12/2002

\begin{tabular}{|c|c|c|c|c|c|c|c|c|c|}
\hline \multirow{2}{*}{ Idade } & \multicolumn{3}{|c|}{ Homens } & \multicolumn{3}{|c|}{ Mulheres } & \multicolumn{3}{|c|}{ População total } \\
\hline & ${ }_{n} \mathbf{r}_{x}$ & $\mathbf{l}_{x}$ & $n^{\mathbf{i}_{x}}$ & ${ }_{n} \mathbf{r}_{x}$ & $\mathbf{l}_{x}$ & $n_{x}^{\mathbf{i}_{x}}$ & ${ }_{n} \mathbf{r}_{x}$ & $\mathbf{l}_{x}$ & ${ }_{n} \mathbf{i}_{x}$ \\
\hline 20 & 0,00009 & 100.000 & 9 & 0,00005 & 100.000 & 5 & 0,00007 & 100.000 & 7 \\
\hline 21 & 0,00017 & 99.991 & 17 & 0,00006 & 99.995 & 6 & 0,00012 & 99.993 & 12 \\
\hline 22 & 0,00024 & 99.974 & 24 & 0,00009 & 99.989 & 9 & 0,00018 & 99.980 & 18 \\
\hline 23 & 0,00033 & 99.950 & 33 & 0,00013 & 99.981 & 13 & 0,00025 & 99.962 & 25 \\
\hline 24 & 0,00041 & 99.917 & 41 & 0,00018 & 99.968 & 18 & 0,00032 & 99.937 & 32 \\
\hline 25 & 0,00051 & 99.876 & 51 & 0,00024 & 99.950 & 24 & 0,00041 & 99.905 & 41 \\
\hline 26 & 0,00062 & 99.825 & 62 & 0,00031 & 99.927 & 31 & 0,00050 & 99.865 & 50 \\
\hline 27 & 0,00073 & 99.763 & 73 & 0,00040 & 99.896 & 40 & 0,00060 & 99.815 & 60 \\
\hline 28 & 0,00085 & 99.690 & 85 & 0,00049 & 99.856 & 49 & 0,00072 & 99.755 & 71 \\
\hline 29 & 0,00099 & 99.605 & 98 & 0,00060 & 99.807 & 60 & 0,00084 & 99.683 & 84 \\
\hline 30 & 0,00113 & 99.506 & 113 & 0,00073 & 99.746 & 72 & 0,00098 & 99.600 & 97 \\
\hline 31 & 0,00129 & 99.394 & 128 & 0,00085 & 99.674 & 85 & 0,00112 & 99.502 & 112 \\
\hline 32 & 0,00145 & 99.266 & 144 & 0,00099 & 99.589 & 99 & 0,00127 & 99.391 & 127 \\
\hline 33 & 0,00163 & 99.122 & 161 & 0,00114 & 99.490 & 113 & 0,00144 & 99.264 & 143 \\
\hline 34 & 0,00182 & 98.960 & 181 & 0,00131 & 99.377 & 130 & 0,00163 & 99.121 & 161 \\
\hline 35 & 0,00205 & 98.780 & 202 & 0,00151 & 99.246 & 150 & 0,00184 & 98.960 & 182 \\
\hline 36 & 0,00229 & 98.578 & 225 & 0,00173 & 99.097 & 171 & 0,00207 & 98.778 & 204 \\
\hline 37 & 0,00254 & 98.352 & 250 & 0,00195 & 98.926 & 193 & 0,00231 & 98.574 & 228 \\
\hline 38 & 0,00282 & 98.103 & 276 & 0,00221 & 98.732 & 218 & 0,00258 & 98.346 & 254 \\
\hline 39 & 0,00313 & 97.826 & 306 & 0,00251 & 98.514 & 247 & 0,00289 & 98.092 & 283 \\
\hline 40 & 0,00350 & 97.520 & 341 & 0,00286 & 98.267 & 281 & 0,00325 & 97.809 & 318 \\
\hline 41 & 0,00391 & 97.179 & 380 & 0,00326 & 97.985 & 320 & 0,00366 & 97.491 & 357 \\
\hline 42 & 0,00437 & 96.799 & 423 & 0,00370 & 97.665 & 362 & 0,00411 & 97.134 & 399 \\
\hline 43 & 0,00486 & 96.376 & 469 & 0,00419 & 97.304 & 408 & 0,00460 & 96.735 & 445 \\
\hline 44 & 0,00540 & 95.907 & 518 & 0,00474 & 96.896 & 460 & 0,00515 & 96.290 & 496 \\
\hline 45 & 0,00600 & 95.389 & 572 & 0,00538 & 96.437 & 519 & 0,00576 & 95.794 & 552 \\
\hline 46 & 0,00662 & 94.817 & 628 & 0,00607 & 95.918 & 582 & 0,00641 & 95.243 & 610 \\
\hline 47 & 0,00727 & 94.189 & 685 & 0,00680 & 95.336 & 648 & 0,00709 & 94.633 & 671 \\
\hline 48 & 0,00798 & 93.504 & 746 & 0,00761 & 94.688 & 721 & 0,00784 & 93.962 & 736 \\
\hline 49 & 0,00878 & 92.758 & 814 & 0,00855 & 93.968 & 803 & 0,00869 & 93.226 & 810 \\
\hline 50 & 0,00969 & 91.944 & 891 & 0,00966 & 93.164 & 900 & 0,00968 & 92.416 & 894 \\
\hline 51 & 0,01068 & 91.052 & 972 & 0,01081 & 92.265 & 998 & 0,01073 & 91.521 & 982 \\
\hline 52 & 0,01172 & 90.080 & 1056 & 0,01199 & 91.267 & 1094 & 0,01183 & 90.539 & 1072 \\
\hline 53 & 0,01289 & 89.024 & 1147 & 0,01337 & 90.173 & 1205 & 0,01308 & 89.467 & 1171 \\
\hline 54 & 0,01423 & 87.877 & 1250 & 0,01510 & 88.968 & 1344 & 0,01459 & 88.297 & 1288 \\
\hline 55 & 0,01581 & 86.626 & 1369 & 0,01738 & 87.624 & 1523 & 0,01644 & 87.009 & 1431 \\
\hline 56 & 0,01761 & 85.257 & 1501 & 0,02015 & 86.101 & 1735 & 0,01866 & 85.578 & 1597 \\
\hline 57 & 0,01958 & 83.756 & 1640 & 0,02330 & 84.367 & 1965 & 0,02117 & 83.981 & 1778 \\
\hline 58 & 0,02176 & 82.116 & 1787 & 0,02687 & 82.401 & 2214 & 0,02396 & 82.203 & 1970 \\
\hline 59 & 0,02418 & 80.329 & 1942 & 0,03091 & 80.187 & 2479 & 0,02701 & 80.233 & 2167 \\
\hline 60 & 0,02686 & 78.387 & 2105 & 0,03546 & 77.708 & 2756 & 0,03031 & 78.066 & 2366 \\
\hline 61 & 0,03050 & 76.281 & 2327 & 0,04093 & 74.952 & 3068 & 0,03446 & 75.700 & 2608 \\
\hline 62 & 0,03506 & 73.955 & 2593 & 0,04727 & 71.885 & 3398 & 0,03946 & 73.092 & 2884 \\
\hline 63 & 0,03951 & 71.361 & 2820 & 0,05385 & 68.487 & 3688 & 0,04439 & 70.208 & 3117 \\
\hline 64 & 0,04281 & 68.542 & 2935 & 0,06005 & 64.799 & 3891 & 0,04836 & 67.092 & 3245 \\
\hline 65 & 0,04395 & 65.607 & 2884 & 0,06528 & 60.908 & 3976 & 0,05048 & 63.847 & 3223 \\
\hline 66 & 0,04363 & 62.724 & 2736 & 0,06995 & 56.932 & 3982 & 0,05137 & 60.624 & 3114 \\
\hline 67 & 0,04251 & 59.987 & 2550 & 0,07447 & 52.950 & 3943 & 0,05161 & 57.510 & 2968 \\
\hline 68 & 0,03959 & 57.437 & 2274 & 0,07825 & 49.007 & 3835 & 0,05033 & 54.541 & 2745 \\
\hline 69 & 0,03379 & 55.163 & 1864 & 0,08070 & 45.172 & 3645 & 0,04660 & 51.796 & 2414 \\
\hline 70 & 0,02401 & 53.299 & 1280 & 0,08123 & 41.526 & 3373 & 0,03950 & 49.383 & 1950 \\
\hline
\end{tabular}

Fonte: MPS/Dataprev.

Nota: ${ }_{n} r_{n}$ : probabilidade que um segurado sobrevivente à idade $x$ tem de se invalidar entre as idades $x$ e $x+n$, dado que ele não se encontra inválido permanentemente para o trabalho; $I_{n}$ : número de sobreviventes segurados expostos ao risco de aposentar por invalidez que atinge a idade exata $x ; n_{n} i_{n}$ número de entradas em aposentadoria por invalidez, entre as idades $x$ e $x+n$. 
invalidez estimadas para os segurados do RGPS, no período 1999-2002, segundo sexo e idade, é importante ressaltar que essas probabilidades representam a experiência de entrada em aposentadoria por invalideze não a entrada em invalidez no seu conceito mais amplo, caracterizada por um risco de se invalidar crescente com o avançar da idade, pois a saúde torna-se mais frágil e os indivíduos são mais suscetíveis às doenças.

A tábua apresentada neste trabalho é adequada para a massa de participantes do RGPS, pois na informação utilizada para a sua construção não estão incluídas as pessoas que, em gozo de outros benefícios, se invalidaram e nem aquelas que, mesmo inválidas, optaram por outro tipo de aposentadoria. A vantagem dessa escolha pode ser econômica, pois o valor do salário-de-benefício para as aposentadorias por idade, por exemplo, é maior do que para as aposentadorias por invalidez, mas também pode ser especialmente burocrática, dado que a comprovação da velhice é mais fácil do que a do estado de invalidez permanente (CASTRO, 1997).

Além disso, o simples fato de a previdência oferecer vários tipos de benefícios ao mesmo tempo torna esses benefícios competitivos entre eles, afetando os valores das probabilidades. Durante toda a vida ativa, os segurados estiveram expostos ao risco de se invalidar ou morrer, ou seja, o benefício de invalidez competiu com o de pensão. A partir do grupo etário de 35-39 anos (Gráfico 5), os segurados que cumpriram, no mínimo, a carência de 180 contribuições mensais começam a se aposentar por tempo de contribuição e, finalmente, após atingirem as idades mínimas para aposentadoria por idade - 65 anos de idade, se homem, ou 60 anos, se mulher, reduzidos esses limites para 60 e 55 anos de idade para os trabalhadores rurais, respectivamente, homens e mulheres -, aqueles que não se aposentaram por tempo de contribuição e cumpriram a carência mínima exigida para a aposentadoria por idade começam a se aposentar por idade.

Ao analisar as probabilidades de entrada em aposentadoria por invalidez para os homens (Tabela 2 e Gráfico 4), observa-se que estas são crescentes até os 65 anos e depois diminuem, continuando a apresentar valores importantes até os 70 anos de idade. Para as mulheres, elas aumentam até a última idade considerada. Até os 40 anos, as entradas em aposentadoria por invalidez são mais acentuadas para os homens.

Se todos os segurados tivessem cumprido a carência mínima exigida para a concessão dos benefícios de aposentadoria programáveis (tempo de contribuição e idade) até a idade mínima para se aposentar por idade e todos se aposentassem ao adquirir a carência, não se deveria esperar a existência de entradas em aposentadoria por invalidez para os segurados do sexo feminino com mais de 60 anos e nem para os segurados homens com mais de 65 anos, uma vez que esse benefício não é concedido para aposentados. No entanto, observam-se entradas em aposentadorias por invalidez após essas idades. Isto se deve, provavelmente, ao fato de uma parte importante dos trabalhadores segurados, especialmente mulheres, não cumprir a carência exigida até a idade mínima de aposentadoria por idade, permanecendo, assim, como segurados e expostos ao risco de se aposentar por invalidez por mais tempo.

Outro fator de destaque é a queda no risco de se aposentar por invalidez para os homens após os 65 anos. Isto parece indicar que os filiados que permanecem em atividade depois dessa idade fazem parte de um grupo seleto, caracterizado por melhores condições de saúde, ou porque muitos dos filiados com saúde mais vulnerável conseguiram uma aposentadoria regular, ou um beneficio assistencial - como o BPC ${ }^{10}$ - ou, simplesmente, porque parte dos indivíduos não tem condições de trabalhar e, por isso, não pode contribuir e manter sua filiação.

Mais uma possível explicação para a queda das probabilidades masculinas após os 65 anos é que o denominador nas últimas idades está provavelmente superestimado, pois possivelmente contempla trabalhadores segurados que satisfazem a carência mínima exigida para a concessão de aposentadoria programada, mas estão

\footnotetext{
10 Benefício de Prestação Continuada.
} 
adiando o requerimento desse benefício. Essa escolha de continuar trabalhando pode ser econômica, pois o valor do salário-debenefício para as aposentadorias por idade é mais vantajoso quanto maior for a idade e o tempo de contribuição (BRASIL, 1999).

Por sua vez, as mulheres apresentaram probabilidades de entrada em invalidez superiores às observadas para os homens após os 50 anos e crescentes até os 70 anos (Tabela 2 e Gráfico 4). Esse padrão pode ser atribuído, em parte, à maior dificuldade das mulheres em satisfazer os critérios exigidos para concessão dos benefícios de aposentadorias por idade e tempo de contribuição, seja porque ingressaram no RGPS tardiamente, seja porque possuem trajetórias de contribuição muito irregulares. Essa hipótese é também fundamentada com base nas análises realizadas anteriormente, quando se verificou que essas mulheres eram, em sua maioria, seguradas individuais e facultativas, especialmente após os 60 anos. Como a carência não foi cumprida até a idade mínima de aposentadoria por idade, essas mulheres permanecem como seguradas e expostas ao risco de se aposentar por invalidez por mais tempo e em maior número. Espera-se que a segurada que cumpriu as exigências para se aposentar por tempo de contribuição ou idade faça o requerimento desses benefícios, mesmo que não esteja apta para o exercício de sua atividade. Essa escolha, mais uma vez, pode ser econômica, mas também burocrática (CASTRO, 1997; BRASIL, 1999).

Por fim, no Gráfico 6, as probabilidades apresentadas na Tabela 2 são comparadas com as probabilidades implícitas em três das principais tábuas utilizadas pelo mercado previdenciário: a tábua Álvaro Vindas (estabelecida pela legislação sobre planos de previdência complementar como limite mínimo para as probabilidades de entrada em aposentadoria por invalidez), a Light e a IAPB-57 (construídas em 1973 e 1957, respectivamente, com base em experiências de invalidez de trabalhadores brasileiros).

GRÁFICO 6

Comparação entre as probabilidades de entrada em invalidez estimadas para os segurados do RGPS e as probabilidades implícitas nas tábuas Álvaro Vindas, Light e IAPB-57 Fraca, segundo idade Brasil - 1999-2002

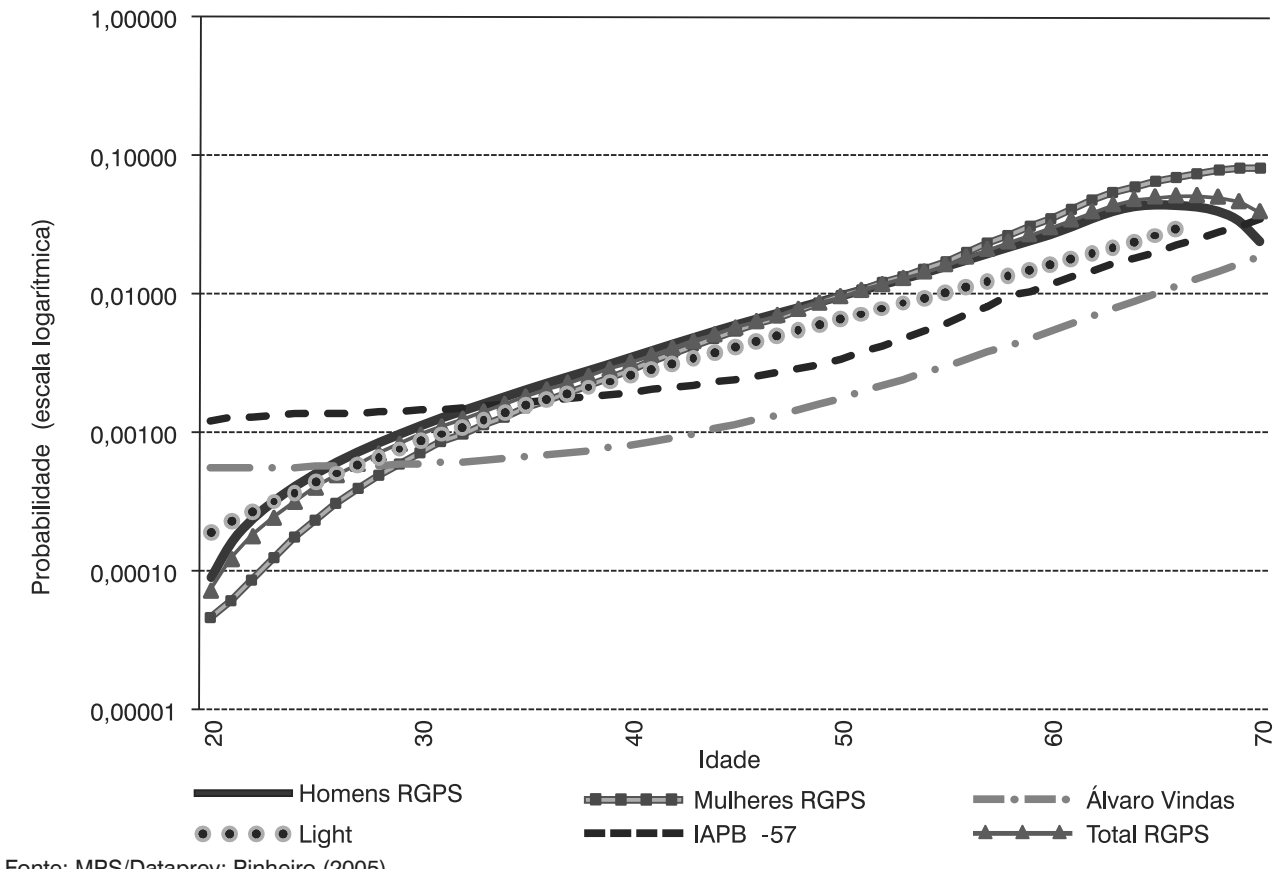

Fonte: MPS/Dataprev; Pinheiro (2005). 
No cômputo geral, as probabilidades comparadas apresentaram níveis e estrutura diferentes. Independentemente do sexo, essas diferenças são maiores a partir dos 50 anos de idade. Outra diferença importante entre as curvas é que, nas tábuas utilizadas pelos planos de previdência, o padrão de entrada em invalidez permanente é sempre crescente, mesmo nas idades mais avançadas. Por sua vez, as probabilidades apresentadas neste trabalho mostram que o número de aposentadorias concedidas após determinada idade tende a diminuir. A Tábua Álvaro Vindas foi a que apresentou padrão mais distante da real experiência de invalidez permanente vivenciada pelos segurados do RGPS.

\section{Considerações finais}

Neste estudo, procurou-se descrever como ocorre a transição do estado de atividade para a invalidez permanente entre os segurados do Regime Geral da Previdência Social. Com esse objetivo, foi construída uma Tábua de Entrada em Aposentadoria por Invalidez, segundo sexo e idade, para o período 1999-2002, com base nos registros administrativos da Dataprev/MPS e nas informações do CNIS sobre contribuintes da previdência social.

Ao analisar o padrão implícito na tábua construída, observou-se que as probabilidades foram crescentes para os homens até os 65 anos e depois diminuíram, continuando a apresentar valores importantes até os 70 anos de idade. Para as mulheres, as respectivas probabilidades foram crescentes até a última idade considerada. A queda das probabilidades masculinas após os 65 anos de idade sugere que os filiados que permanecem em atividade depois dessa idade pertencem a um grupo seleto, caracterizado por melhores condições de saúde, ou

\section{Referências}

MPS/INSS/DATAPREV. Anuário Estatístico da Previdência Social. Brasília, v. 14, 2007. Disponível em: <http://www. previdenciasocial.gov.br/docs/pdf/aeps2005. pdf > . Acesso em: 23 fev. 2007. porque muitos dos filiados com saúde mais vulnerável conseguiram outro benefício, ou, simplesmente, porque parte dos indivíduos não tem condições de trabalhar e, por isso, não pode contribuir e manter sua filiação. As entradas em aposentadorias por invalidez, após as idades limites para concessão de aposentadorias por idade, podem ser explicadas, em parte, pela presença de trabaIhadores, especialmente do sexo feminino, que não cumprem a carência exigida até a idade mínima de aposentadoria por idade e permanecem, assim, como segurados e expostos por mais tempo ao risco de se aposentar por invalidez.

Espera-se que a Tábua de Entrada em Aposentadoria por Invalidez construída e apresentada neste trabalho para os segurados do RGPS seja útil para a Previdência Social na realização de projeções ou simulações do número de beneficiários aposentados por invalidez. Ao mesmo tempo, as probabilidades estimadas poderão ser utilizadas pelo mercado previdenciário como uma referência na escolha de tábuas de entrada em aposentadoria por invalidez, especialmente para os fundos de pensão, pois essas probabilidades representam a experiência de entrada em invalidez permanente mais próxima da realidade brasileira, quando comparadas com as probabilidades das outras tábuas utilizadas pelo mercado previdenciário. Além disso, todos os participantes de entidades de previdência complementar fechada estão vinculados ao RGPS (MPS, 2007). Ressalta-se, porém, que as probabilidades apresentadas não incluem as aposentadorias por invalidez acidentárias, pois estas possuem características e regras diferenciadas de concessão, quando comparadas às previdenciárias e representam apenas $4,9 \%$ das aposentadorias por invalidez concedidas pelo RGPS no período em estudo.

\footnotetext{
BASE DE DADOS HISTÓRICOS DO ANUÁRIO ESTATÍSTICO DA PREVIDÊNCIA SOCIAL. InfoLogo, 2007. Disponível em: <http://www3.dataprev.gov.br/infologo/ inicio.htm>. Acesso em: 15 out. 2009.
} 
BRASIL. Constituição: República Federativa do Brasil. Brasília: Horizonte Editora, 1988.

Decreto n. 3.048 de 6 de maio de 1999. Diário Oficial da União, Brasília, seção I, p.50-108, 07 maio 1999. Disponível em: <http://www.prece.com.br/images/new/ legislacao/DECRETO_3.048_DE_6_\%20 MAIO_1999.pdf>. Acesso em 23 fev. 2007.

Emenda Constitucional n. 20 de dezembro de 1998. Diário Oficial da União, Brasília, 16 dez. 1998. Disponível em: <http://www010.dataprev.gov.br/sislex/ paginas/30/1998/20.htm>. Acesso em: 12 abr. 2007.

Lein. 8.213 de 24 de julho de 1991. Diário Oficial da União, Brasília, 25 jul. 1991. Disponível em: <http://www81.dataprev.gov. br/sislex/paginas/42/1991/8213_7.htm>. Acesso em: 12 abr. 2007.

CASTRO, M. C. de. Entradas e saídas no sistema previdenciário brasileiro: uma aplicação de tábuas de mortalidade. Dissertação (Mestrado em Demografia) - Centro de Desenvolvimento e Planejamento Regional, Universidade Federal de Minas Gerais, 1997.

MPS - Ministério da Previdência Social. Coletânea de normas dos fundos de pensão. 3 ed. Brasília: MPS, SPC, 2007.

CNSP - Conselho Nacional de Seguros Privados. Resolução n. 092 de 30 de setembro de 2002. Diário Oficial da União, Brasília, 10 out. 2002. Disponível em: <http://www. susep.gov.br/textos/resol092.htm>. Acesso em: 23 mar. 2007.

IBGE/DEPIS - Instituto Brasileiro de Geografia e Estatística/Departamento de População e Indicadores Sociais. Estimativas preliminares de tabelas de sobrevivência: Brasil e UF's, 1991-2010. Disponível em: <http:// www.ibge.gov.br>. Acesso em: abr. 2007.

JORDAN, C. W. Life contingencies. 2. ed. Chicago: Society of Actuaries, 1967.

MAGALHÃES, P. B. de C.; BUGARIN, M. N. S.Simulações da previdência social brasileira: estudo de caso do Regime Jurídico Único RJU. Estudos Econômicos, São Paulo, v. 34, n. 4, p. 627-659, out./dez. 2004. Disponível em: <http://www.econ.fea.usp.br/novo_site/ publicacoes/estudos_economicos/34_4/ magalhaes-bugarin.p $\overline{d f}>$. Acesso em: 22 jun. 2007.

MPAS - Ministério da Previdência e Assistência. Portaria n. 4.992 de 05 de fevereiro de 1999. Diário Oficial da União, Brasília, 08 fev. 1999. Disponível em: < http:// www81.dataprev.gov.br/sislex/paginas/66/ mpas/1999/4992.htm >. Acesso em: 23 mar. 2007.

OLIVEIRA, F. E. B. de (Coord.). Tendências a médio prazo da previdência social brasileira: um modelo de simulação. Rio de Janeiro: Ipea, 1985 (Textos para discussão interna, 73).

OLIVEIRA, F. E. B. de; BELTRÃO, K. I.; PINHEIRO, S. S.; PEYNEAU, F. P. L.; MENDONÇA, J. L. O. O idoso e a previdência social. In: CAMARANO, A. A. (Org.). Os novos idosos brasileiros: muito além dos 60? Rio de Janeiro: Ipea, 2004, p. 411-426.

PINHEIRO, R. P. Riscos demográficos e atuariais nos planos de benefício definido e de contribuição definida no fundo de pensão. Tese (Doutorado em Demografia) Centro de Desenvolvimento e Planejamento Regional, Universidade Federal de Minas Gerais, 2005.

RIBEIRO, A. J. F. Um estudo sobre mortalidade dos aposentados por invalidez do Regime Geral de Previdência Social (RGPS). Tese (Doutorado em Demografia) Centro de Desenvolvimento e Planejamento Regional, Universidade Federal de Minas Gerais, 2006.

SEAL, H. L. Studies in the history of probability and statistics: multiple decrements or competing risks. Biometrika, v. 64 , n. 3 , p. 429-439, Dec. 1977.

SHRYOCK, H. S.; SIEGEL, S. J. The methods and materials of demography. Washington: U. S. Government Printing Office, 1980.

SIEGEL, S. J.; SWANSON, D. A. The methods and materials of demography. Second Edition. USA: Elsevier Academic Press, 2004. 
VICENTE MERINO, A. et al. Análisis dinámico de la invalidez: aplicácion a los seguros de riesgo. Actuarios, n. 21, p. 201-224, Abr./ Mayo 2003. Disponível em: <http://www. actuarios.org/espa/revista21/invalidez. htm >. Acesso em: 22 mar. 2007.
WINKLEVOSS, H. E. Pension mathematics with numerical illustrations. Second Edition. Philadelphia: University of Pennsylvania, 1993.

\section{Resumen}

De la actividad a la invalidez permanente: un estudio utilizando datos del Régimen General de la Seguridad Social (RGPS) de Brasil en el período 1999-2002

Este trabajo tiene como objetivo estimar las probabilidades de transición de un individuo entre los estados de actividad e invalidez permanente, según el sexo y edad, para los asegurados del Régimen General de Seguridad Social -RGPS en el período 1999-2002. Los resultados muestran que el riesgo de jubilarse por invalidez, para los hombres, es creciente hasta los 65 años de edad y después disminuye. Para las mujeres, las probabilidades de entrada en una jubilación por invalidez son crecientes hasta la última edad considerada. El patrón observado puede ser explicado, entre otros motivos, debido a la competitividad del riesgo de jubilarse por invalidez con los demás beneficios cubiertos por el sistema de la seguridad social, en caso de que el asegurado haya pospuesto o no haya cumplido la carencia mínima exigida para requerir la concesión de tales beneficios. Por ser una tabla adecuada para la masa de participantes de un régimen de la seguridad social, este trabajo contribuye a un mayor conocimiento sobre la invalidez, principalmente en las áreas de seguros y seguridad social.

Palabras-clave: Tablas de vida. Seguridad social. Invalidez permanente.

\section{Abstract}

From working to permanent disability: a study based on data from the General Social Security Regime (RGPS) in Brazil from 1999 to 2002

This article has the objective of estimating the probability that individuals registered with the General Social Security Regime (RGPS) in Brazil would pass from the state of working to that of permanent disability, by sex and by age, from 1999 to 2002. The results show that the risk of men retiring due to disability rises with age until the age of 65 , and then falls. For women, the probability of retiring due to permanent disability continues to rise up to the highest age measured. This pattern can be explained in part by the competition between, on the one hand, the risk of retiring due to disability and, in contrast, other benefits provided by the Brazilian social security system to individuals who have postponed retirement or have not yet fulfilled the minimum requirements for such. Since the information in this article refers to the vast majority of persons registered with the social security regime, it is intended as a contribution for a broader understanding of disability, especially in the areas of insurance and social security.

Keywords: Life tables. Social security. Permanent disability.

Recebido para publicação em 28/06/2009 Aceito para publicação em 03/03/2010 